\title{
Primary immunodeficiency syndrome due to LAMTOR2 deficiency
}

INSERM

\section{Source}

INSERM. (1999). Orphanet: an online rare disease and orphan drug data base. Primary immunodeficiency syndrome due to LAMTOR2 deficiency. ORPHA:90023

Primary immunodeficiency syndrome due to p14 deficiency is characterised by short stature, hypopigmentation, coarse facies and frequent bronchopulmonary Streptococcus pneumoniae infections. 